\title{
NASTAVNIK ISLAMSKE VJERONAUKE U SAVREMENOJ ŠKOLI
}

\section{Sažetak}

Savremene promjene u obrazovanju $i$ uloga koju to ima u procesu nastave islamske vjeronauke zabtijevaju od nastavnika da bude osoba od povjerenja, odgajatelj, savjetodavac, prijatelj, organizator, koordinator, saradnik, inovator, mentor - jednom riječju svestrana ličnost. Nastavniku islamske vjeronauke će u svim situacijama uzor biti Allahov Poslanik. „Vi u Allahovom Poslaniku imate divan uzor za onoga koji se nada Allahovoj milosti i nagradi na onom svijetu $i$ koji cesto Allaha spominje." (Kur'an, El-Azhab, 21) Poslanik, a.s., je bio na najvećem stupnju morala. Gospodar ga je odabrao među ostalim stvorenjima i najljepši mu odgoj dao. Bio je čestit i posten, istinoljubiv i pravedan. Rad ima za cilj dati osnovne smjernice nastavniku islamske vjeronauke, a ticu se njegovih poželjnih osobina, kreativnosti u radu i podućavanju u nastavi islamske vjeronauke. Od nastavnika $i$ njegovog stila weliko zavisi i uspjeh u nastavi.

Ključne riječi: nastavnik, savremena nastava, kreativnost $i$ inovativnost.

\section{Uvod}

S obzirom da živimo u vremenu koje je bogato informacijama i sredstvima za stjecanje znanja, jako je bitno da razvijamo sposobnosti za njegovo brže i kvalitetnije usvajanje. $U$ tom smislu i nastavnik islamske vjeronauke treba i mora da se obrazuje doživotno. Nastavnik je izuzetno značajan učesnik u nastavi i imajući u vidu ovu ulogu, možemo sa sigurnošću reći da uspješnost u nastavi islamske vjeronauke prvenstveno zavisi od nastavnika. Od njega zavisi kvaliteta nastave. Da bi ta kvaliteta bila što bolja, nastavnik mora svoj rad prilagoditi ostalim činiocima nastave, prvenstveno učenicima, njihovim intelektualnim sposobnostima, predznanju, interesovanjima, motivaciji. Ovaj rad ima za cilj baviti se pitanjima bitnim za uspješno funkcionisanje nastavnika islamske vjeronauke u savremenoj nastavi. To se prvenstveno odnosi na njegovu ulogu u nastavi, tj. na inovativnost i kreativnost, otvorenost prema promjenama u obrazovanju i uspješno podučavanje u nastavi islamske

\footnotetext{
${ }^{1}$ Islamski pedagoški fakultet u Bihaću.
} 
vjeronauke. Naglasak je stavljen na poželjne osobine nastavnika islamske vjeronauke.

$\mathrm{U}$ našem odgojno-obrazovnom radu, iako su poduzeti mnogobrojni napori i pozitivne pedagoško-psihološke mjere u oblasti reforme i modernizacije osnovnih škola, i dalje su prisutni zastarjeli načini rada i primjenjivanje zastarjelih metoda rada. Ova realnost treba biti poticaj svim nastavnicima da poduzmu odgovarajuće mjere kako bi se ovakva situacija promijenila u pozitivnom smislu.

\section{Poželjne osobine nastavnika islamske vjeronauke}

Vi u Allabovom Poslaniku imate divan uzor za onoga koji se nada Allahovoj milosti i nagradi na onom svijetu $i$ koji često Allaha spominje. (Kur'an, El-A₹̧ab, 21)

Nastavnik islamske vjeronauke će u svim situacijama imati primjer Allahovog Poslanika, a.s. Poslanik, a.s., je bio na najvećem stupnju morala. Njega je njegov Gospodar odabrao među ostalim stvorenjima i najljepši mu odgoj dao. Bio je čestit i pošten, istinoljubiv i pravedan. Šalio bi se sa svojim ashabima, družio se s njima i razgovarao, zabavljao se s njihovom djecom i držao ih u svom krilu. On je bio najbrižniji roditelj i idealni suprug, imam koji se savjetuje s drugima, hrabri vojskovođa i mudri vladar. On je najbogobojazniji musliman. Bio je pun pažnje prema svakome.

Ako imamo sve ovo u vidu, pa zar trebamo tražiti mišljenja pedagoga o osobinama koje treba da posjeduje nastavnik? Dobar nastavnik islamske vjeronauke će u svakom momentu znati da je pred njim odgovoran zadatak.

\subsection{Kvalitetan nastavnik islamske vjeronauke je primjer učenicima u blagom ophođenju i savjetovanju}

Na put Gospodara svoga mudro i lijepim savjetom pozivaj $i$ s njima na najljepši način raspravljaj! Gospodar tvoj zna one koji su zalutali s puta Njegova $i$ On zna one koji su na Pravom putu. (Kur'an, En-Nabl, 125)

U Kur'anu se na mnogo mjesta može naći primjer savjeta, lijepog ophođenja. Allah, dž. š., među prvim sredstvima odgojnog rada ističe upravo savjet. Božiji Poslanik, a.s., je bio prirodan, iskren i nenametljiv, a njegovi savjeti aktuelni, konkretni, jasni, razumljivi, logični, uvjerljivi i 
prihvatljivi. Nastavnik islamske vjeronauke će u svakoj situaciji imati Kur'an i primjer Božijeg Poslanika, a.s. Dobar nastavnik zna da nije moguće izbjeći pogreške koje se javljaju u procesu učenja. On zna da učenik može pogriješiti, a da za to ne bude ukoren. Ako učenik ne smije pogriješiti, onda se u poduku uvodi najveća prepreka učenju - strah. Dobar nastavnik zna da je učenje putem pokušaja i pogrešaka složen i važan oblik učenja koji se nipošto ne smije isključiti iz procesa podučavanja u nastavi islamske vjeronauke.

U svakoj životnoj situaciji se skrivaju određene prilike za učenje i dobar nastavnik zna kako svojim podučavanjem uputiti učenike na njih. Potrebno je da osluškuje želje i potrebe svojih učenika te da ih potiče da svaku priliku iskoriste za učenje. Nastavnik mora biti osoba koja pomaže učenicima u učenju. On treba da jača njihovu samostalnost i odgovornost. Međutim, vrlo često možemo čuti nastavnike kako okrivljuju učenike za ono što nisu učinili, a bili su dužni. Prečesto ih okrivljuju za poteškoće i probleme u učenju što je pogrešno, žale se na njihovu slabu zainteresiranost, na njihovo učenje i pasivnost. Ako nastavnik želi postići uspjeh u učenju, onda treba prestati sa kritiziranjem i okrivljavanjem učenika. Podučavanje ne može biti uspješno ukoliko je zasićeno lošim riječima i kritikama. $\mathrm{Na}$ taj način navikavamo dijete da često čuje kritike i loše riječi, što može biti veoma loše za njegovo samopouzdanje u daljnji napredak. Kur'an nas obavezuje da ne smijemo biti grubi prema drugima i da im uvijek govorimo lijepe riječi. Reci robovima Mojim da govore samo lijepe riječi. (17:53)

Vrlo često se na sjednicama u školi može čuti razgovor između nastavnika o tome kako se učenici neposlušno ponašaju, ne uče, nisu motivisani i postižu slabe rezultate kao da su jedino oni odgovorni za učenje. Bude li imao na umu činjenicu da su za uspjeh u učenju jednako odgovorni i učenici i nastavnici, nastavnik islamske vjeronauke će se trudit da zajedno postignu dobre rezultate.

\subsection{Poslovna strana podučavanja i profesionalnost nastavnika islamske vjeronauke}

Poučavanje učenika o vjeri je zahtjevna profesija koja iziskuje ispravne stavove, umijeća, znanje $i$ iskustvo. Što više razmišljate o sebi kao o nastavniku kojem je uloga prenijeti osnovna znanja o vjeri i moralu, to ćete biti bolje osposobljeni za posao nastavnika. Osnovni 
zadatak nastavnika kada počne raditi jeste otkriti i naučiti što više o školi u kojoj radi. Savjetuje se slijedeće:

- otkrijte šta su drugi nastavnici radili u školi prije vas,

- pregledajte školske arhive,

- čitajte stare školske listove i novine,

- $\quad$ saznajte ko su ključni ljudi iz prošlosti i sadašnjosti bitni za razvoj škole,

- upoznajte druge nastavnike i važne osobe u školi kao što su sekretar, stručni saradnici (pedagog, psiholog, bibliotekar, logoped),

- pronadite i koristite nastavna sredstva, ukoliko ih škola ne posjeduje - potražite izvore za njihovu nabavku.

Ukoliko, kao nastavnik, želite da vas drugi poštuju, poštujte sami sebe. Želite li da se s vama postupa kao sa profesionalcem - tako se i ponašajte. Trebalo bi poslušati nekoliko savjeta:

- obucite se profesionalno,

- budite tačni - kašnjenje na posao je ružan primjer učenicima i kolegama,

- čitajte stručne časopise,

- pratite novija dešavanja u vašoj struci,

- budite aktivan član stručnih aktiva nastavnika islamske vjeronauke. bude:

Chris Kyriacou (1998.) smatra da savremeni nastavnik treba da

1. samouvjeren, srdačan i jubazan,

2. profesionalan,

3. poticajan,

4. pokeretlïi,

5. sa smislom za bumor,

6. da više uspostavlja kontakt očima sa ǘenicima,

7. da ima jasno propisana pravila, 
8. da se zna nametnuti i osobno i svojim autoritetom. ${ }^{2}$

Savremeni nastavnik mora imati više razumijevanja i više znanja od običnih ljudi. Tomas Gordon smatra da je dobar nastavnik:

1. miran, spokojan, uvijek dobro raspoložen, nikad ne gubi pribranost $i$ nikad ne pokazuje snažna osjećanja,

2. dobar nastavnik nema preduvjerenja i predrasude: glupa djeca, pametna djeca, djevojčice, dječaci, konfesija, ime - svi su oni isti dobrom nastavniku; on ne pravi razlike među imenima ni spolovima,

3. on može sakriti svoja osjećanja od učenika i on to čini,

4. on na isti način prihvata sve učenike; dobar nastavnik nikada nema omiljene učenike u razredu,

5. on osigurava da radna sredina uvijek bude zanimljiva, stimulativna i slobodna, ali u svako doba tiha i uredna,

6. on je dosljedan, ne zaboravlja, ne mijenja raspoloženja i ne pravi greške,

7. on zna odgovore, on je mudriji od učenika,

8. on podržava druge kolege nastavnike.

\subsection{Otvorenost prema promjenama u obrazovanju}

Promjene u obrazovanju odnose se na promjene u pripremi, organizaciji i realizaciji obrazovnog rada u obrazovnoj praksi i vezane su za društvene, modernizacijske, tehničko-tehnološke promjene koje su desile i koje se dešavaju u društvu, a koje neminovno uslovljavaju i promjene u sferi obrazovanja. Promjene u obrazovanju podrazumijevaju pravo učenika i njihovih roditelja da biraju kvalitetniju školu, kvalitetnije nastavnike, udžbenike, metode i programe rada. Nastavnik u promjenama u obrazovanju ima šansu da bira kvalitetnije i kreativnije metode u svom radu, da na moderniji i kreativniji način interaktivnim metodama potiče učenike na kreativan $i$ istraživački rad u nastavi islamske vjeronauke. $\mathrm{Na}$ taj način ima šansu da stalno uči i napreduje u svom radu i da postane napredan i cijenjen. On više nije predavač i jedini izvor saznanja - on je kreator rada i organizator istraživačkog rada učenika u otkrivanju novih spoznaja.

${ }^{2}$ Chris Kyriacou, Temeljna nastavna umijeća, Educa, Zagreb, 1995., 85-86 str. 


\section{Kreativnost $i$ inovativnost nastavnika islamske vjeronauke}

Biti nastavnik islamske vjeronauke u današnjoj školi znači radovati se zajedničkim uspjesima sa učenicima, uživati u veselom školskom okruženju, stvarati pozitivnu klimu u odjeljenju i u školskom kolektivu. On mora znati uživati u vrlo zahtjevnom poslu koji od njega traži kreativnost. Prilikom svog rada nastavnik mora uvijek pronalaziti inovacije i dosta istraživati kako bi njegov rad zadovoljio sve potrebe današnjih učenika i savremenog društva.

Jedna od bitnih karakteristika inovativnog nastavnika jeste da potiče učenike na kreativnost u nastavi islamske vjeronauke. Učenik radeći kreira, a kreirajući putem svojih osjetila organizira misaonu aktivnost koja dovodi do novih otkrića, inovacija, izuma ili originalnih rješenja zadataka u konkretnoj problemskoj situaciji. Putevi koji vode razvoju kreativnosti su dostupni i primjenljivi za sve škole i nastavnike.

Da bismo razvili kreativnost trebamo:

1. kreirati učenicima okolinu u kojoj će se osjećat sigurni, slobodni i socijalno prihvaćeni,

2. učenike ohrabrivati da razmjenjuju ideje, ne samo sa nastavnikom nego i između sebe,

3. nastojati što manje primjenjivati sistem natjecanja i nagradivanja,

4. kreirati slobodno i otvoreno okruženje, ohrabriti i cijeniti samoizražavanje. 


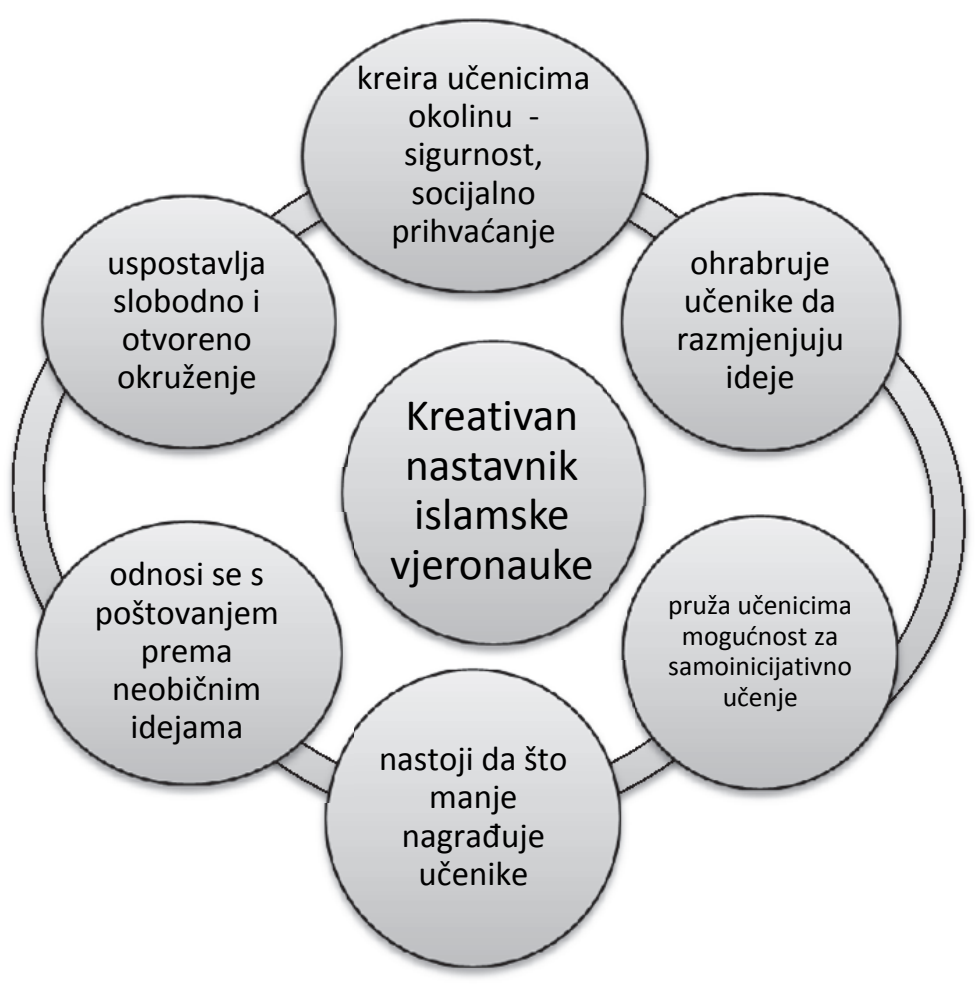

Za poticanje kreativnih učenika Torens predlaže slijedeće principe:

1. odnositi se spoštovanjem prema neobičnim idejama,

2. pokazati djeci da njihove ideje imaju vrijednost,

3. pruq̌iti mogućnost za samoinicijativno učenje i pokazati povjerenje za takav rad,

4. obębijediti periode rada i ǔ́enja koji se ne procjenjuju.

\section{Zaključak}

Promjene u društvu koje utječu na promjene u školi se $u$ najvažnijem dijelu odnose na promjene pozicije nastavnika i njegove uloge i stila rada u nastavnom procesu. Nastavnik treba da bude pedagoški subjekt koji je sposoban i spreman u drugima probuditi želju za znanjem i propagirati ispravne vrijednosti.

3 Mandić P.,Gajanović N.; Psihologija u službi učenja i nastave, Grafokomerc Tunjić, Lukavac, 1991.,282 str. 
Dobar nastavnik zna da nije moguće izbjeći pogreške koje se javljaju u procesu učenja. On zna da učenik može pogriješiti, a da ne bude ukoren. Ako učenik ne smije da pogriješi, onda se u poduku uvodi najveća prepreka učenju - strah. Dobar nastavnik zna da je učenje putem pokušaja i pogrešaka složen i važan oblik učenja koji se nipošto ne smije isključiti iz procesa podučavanja u nastavi islamske vjeronauke.

Vrlo često se na sjednicama u školi mogu čuti nastavnici kako komentarišu da su učenici neposlušni, da ne uče, da nisu motivisani i postižu slabe rezultate kao da su jedino učenici odgovorni za to. Bude li imao na umu činjenicu da su za uspjeh u učenju jednako odgovorni i učenici i nastavnici, nastavnik islamske vjeronauke će se trudit da zajedno postignu dobre rezultate.

Biti nastavnik islamske vjeronauke u današnjoj školi znači radovati se zajedničkim uspjesima, uživati u veselom školskom okruženju, stvarati pozitivnu atmosferu u odjeljenju i u školskom kolektivu. On mora znati uživati u ovom vrlo zahtjevnom poslu koji od njega traži kreativnost. Nastavnik mora uvijek tragati za inovacijama u svom području i truditi se da bude kreativan kako bi njegov rad zadovoljio sve potrebe današnjih učenika i savremenog društva.

\section{Literatura}

1. Chris Kyriacou, Temeljna nastavna umijeća, Educa, Zagreb, 1995.

2. Eric Jensen, Super nastava - Nastavne strategije za kvalitetnu školu i uspješno učenje, Educa, Zagreb, 2003.

3. Hasanović, Zuhdija, „Sredstva odgoja kojima se koristio Božiji Poslanik alejhi-sselam“, Muallim, god.III, broj 5, sarajevo 2002.

4. Mandić P.,Gajanović N.; Psibologija u službi učenja i nastave, Grafokomerc Tunjić, Lukavac, 1991.

5. Tomas Gordon, Kako biti uspješan nastavnik, Kreativni centar, Beograd, 1998.

6. Topoljak, Sulejman, Poslanikove odgojne metode, Muallim, god. II, broj 5, Sarajevo, 2001. 
Sebila Bapic, MA

\title{
TEACHER OF ISLAMIC RELIGIOUS EDUCATION IN A CONTEMPORARY SCHOOL
}

\begin{abstract}
Contemporary changes in education and the role which a teacher has in the educational process require that the teacher of Islamic religious education must be a person of trust, educator, adviser, friend, organizer, coordinator, collaborator, innovator, mentor. He bas to be a versatile personality.

The teacher of Islamic religious education has to follow the example of the Holy Prophet, alaybi-s-salam, in all situations: „There has certainly been for you in the Messenger of Allah an excellent pattern for anyone whose hope is in Allah and the Last Day and [who] remembers Allah often." (Qur'an, Al-Azhab, 21) The Prophet, alaybi-s-salam was at the highest level of morality. Lord has chosen him among other creatures and gave him a beautiful upbringing. He was a decent and honest, truthful and fair. This work aims to provide basic guidance to the teacher of Islamic religious education regarding his desirable traits, creativity in work and teaching. The success in the classroom largely depends on the teacher and his style.
\end{abstract}

Keywords: teaching, modern teaching, creativity and innovation. 


\section{م. سبيلة بابيتش}

\section{أستاذ التربية الإسلامية في المدرسة المعاصرة}

\section{الخلاصية}

الأساليب المعاصرة في التعليم ودور أستاذ التربية الإسلامية في عملية التعليم

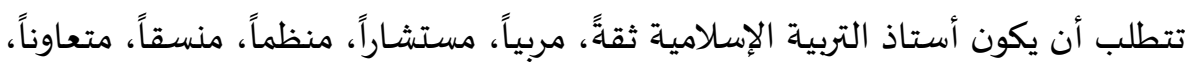

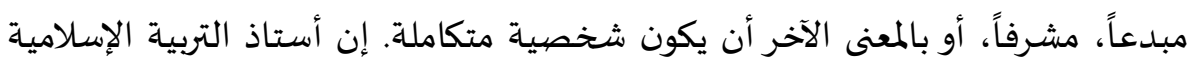

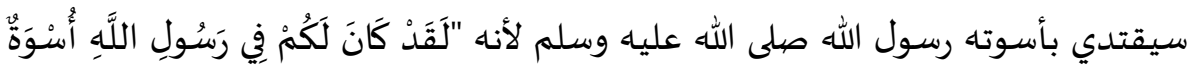

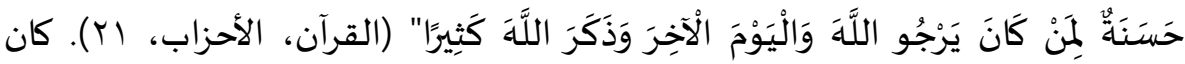

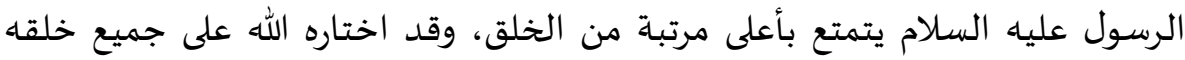

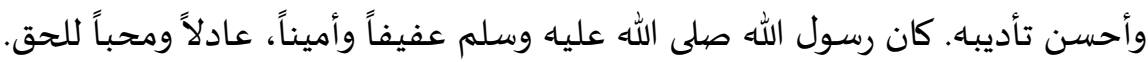
إن هدف البحث أن يعطي أهم التوجيهات لأستاذ التربية الإسلامية تتعلق

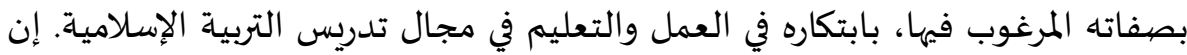
النجاح في التدريس مرهون إلى حد كبير بالأستاذ وأسلوبه.

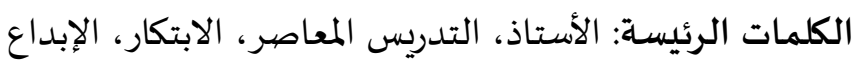

